\title{
ENTREVISTA COM A PROFESSORA EDAIR MARIA GÖRSKI, NOSSA HOMENAGEADA
}

\author{
Carla Regina Martins Valle | Lattes | carlavalle10@gmail.com \\ Universidade Federal de Santa Catarina
}

Cláudia Andrea Rost Snichelotto | Lattes | claudiarost@uffs.edu.br

Universidade Federal da Fronteira Sul

\section{Introdução}

Coube a nós a desafiadora tarefa de entrevistar a professora Edair Maria Görski, nossa orientadora de mestrado e doutorado, parceira de publicações, projetos e eventos e homenageada nesta edição da revista Working Papers em Linguística.

Procuramos lançar questionamentos que levassem a professora Edair a rememorar sua jornada como pesquisadora e que possibilitassem uma retomada dos principais temas que foram e são objeto de seu interesse. Entendemos que as respostas concedidas pela professora refletem sua sólida carreira na UFSC e seu olhar para a língua em uso, que integra multifuncionalidade, variação e mudança, considerando aspectos sociais, identitários/estilísticos e culturais constitutivos das línguas.

Nessas preciosas páginas, a professora Edair nos conta sobre sua atuação no Núcleo Interinstitucional de Pesquisa VARSUL - Variação Linguística na Região Sul do Brasil; recupera os passos para a construção das interfaces sociofuncionalistas no Brasil, defendendo maior espaço para o componente social; evidencia sua aderência a uma visão ampla de gramática (que inclui a pragmática) e de gramaticalização; problematiza os impactos das mudanças sociais da sociedade contemporânea nos estudos de variação e gramaticalização; considera a importância da observação dos diferentes gêneros textuais/ discursivos nos estudos variacionistas, funcionalistas e de interface e destaca as principais contribuições da Sociolinguística e do Funcionalismo na formação e atuação dos/as professores/as da Educação Básica. A entrevista é concluída com uma sensível reflexão da professora sobre o momento pandêmico atual e sobre a desafiadora tarefa de mulheres pesquisadoras em conciliar os diferentes papéis sociais que exercem, culminando em uma retrospectiva de sua trajetória pessoal como professora, pesquisadora, orientadora, filha, mulher, mãe e avó. 
Convidamos leitores e leitoras a conferir nossa entrevista, gentilmente concedida pela professora Edair Maria Görski por e-mail no primeiro semestre de 2021 em meio aos desafios enfrentados em decorrência da pandemia da COVID-19, e conhecer um pouco da história e da trajetória acadêmica da Eda, como preferimos chamar: exemplo de postura ética, pesquisadora de espírito em constante renovação, orientadora que deixa criar e sonhar e professora comprometida com o ensino público, gratuito e de qualidade.

\section{Entrevista}

Valle e Snichelotto: Profa. Edair, seu ingresso na UFSC na década de 1990 é marcado por sua vinculação ao Varsul - Variação Linguística na Região Sul do Brasil, projeto responsável pela constituição de um banco de dados linguístico dos três estados da Região Sul. Refletindo sobre a sua trajetória no projeto, qual a relevância desse tipo de banco de dados para a realização de pesquisas sobre variação e para o desenvolvimento de trabalhos em perspectiva baseada no uso?

Edair Görski : O banco de dados Varsul foi constituído na década de 1990, com entrevistas sociolinguísticas realizadas em 12 cidades (a capital e mais três cidades etnicamente representativas de cada estado da Região Sul - Paraná, Santa Catarina e Rio Grande do Sul), reunindo 288 gravações transcritas (24 por cidade) com informantes de zona urbana estratificados por faixa etária, sexo/gênero e escolaridade, como se pode conferir em http://www.varsul.org.br. A formação desse banco de dados seguiu a mesma orientação metodológica utilizada pelo Projeto Censo-Peul/UFRJ, que tem inspirado a criação de outros bancos de dados sociolinguísticos em diversas instituições brasileiras. Além dessa amostra básica, o Núcleo Varsul continua armazenando novas amostras, tanto de fala como de escrita, ampliando consideravelmente seu banco de dados de modo a possibilitar inúmeras pesquisas das quais tem resultado uma farta produção de teses e dissertações, artigos e livros sobre a descrição do português falado na Região Sul, principal objetivo do Varsul. (VANDRESEN; COELHO, 2008).

Tive o privilégio de participar diretamente da constituição desse banco de dados e da realização concomitante de pesquisas descritivas, tanto minhas como de orientandos na graduação e na pós-graduação. Cabe aqui um registro e um agradecimento especial: deve-se ao professor Paulino Vandresen, coordenador geral do Projeto Varsul à época, o

\footnotetext{
${ }^{1}$ Gostaria de agradecer à Cláudia e à Carla por esta oportunidade de falarmos sobre Sociofuncionalismo e alguns desafios teórico-metodológicos que vêm sendo colocados às propostas de articulação entre a Sociolinguística Variacionista e o Funcionalismo, especialmente no que diz respeito à dimensão sócio da interface em relação com a gramaticalização, questões que vêm recebendo atenção de pesquisadores envolvidos com essa interface na UFSC..
} 
incentivo constante por conduzir paralelamente a organização da amostra e a descrição sociolinguística dos dados coletados - caminho que a professora Izete Lehmkuhl Coelho e eu (e mais tarde outros professores vinculados ao Varsul) nos empenhamos em seguir com nossos orientandos desde a década de 1990, especialmente na UFSC. Outro registro especial é que as duas interlocutoras desta entrevista - as quais tive o privilégio de orientar e com as quais continuo mantendo frutíferas parcerias -, também integraram o Projeto Varsul desde a década de sua criação.

Acredito que essa contextualização é um indicativo da relevância de bancos de dados formados por entrevistas sociolinguísticas para estudos de variação e mudança linguística (três décadas se passaram desde as primeiras gravações do Varsul!), tanto na área da Sociolinguística Variacionista como na área do Funcionalismo, considerando, por exemplo, a multifuncionalidade de itens linguísticos, fenômenos em gramaticalização e, mais recentemente, padrões de esquemas construcionais.

Vale destacar ainda que os diversos bancos de dados que vêm sendo formados no Brasil possibilitam a realização de pesquisas comparativas de modo que os resultados podem ser usados num mapeamento descritivo de fenômenos variáveis no $\mathrm{PB}$, a exemplo do que se encontra na coletânea organizada por Marco Martins e Jussara Abraçado (2015).

Valle e Snichelotto: Na década de 1980 iniciam-se os movimentos de aproximação entre a Sociolinguística laboviana e o Funcionalismo de vertente norte-americana no Brasil. De lá para cá, têm ganhado espaço interfaces Sociofuncionalistas, dentre elas aquela sedimentada por você e seus orientandos. Fale um pouco sobre esse histórico e sobre as bases para a interface.

Edair Görski: O movimento inicial de aproximação entre a Sociolinguística Variacionista (SV) laboviana e o Funcionalismo (FUNC) de vertente norte-americana no Brasil se deu no âmbito do Projeto Peul-UFRJ ainda na década de 1980, com Anthony Naro, Sebastião Votre e orientandos, que acabaram levando para outras instituições esse tipo de abordagem. Os trabalhos pioneiros nessa interface tinham foco na variação e consideravam a forma, em diferentes níveis linguísticos, como variável dependente; e a função, entendida como significação semântico-pragmática-discursiva, como variável independente (como status informacional, por exemplo), no sentido de que a segunda motiva e explica a primeira (cf. NARO; VOTRE, 1992). Trata-se de um tipo de interface que continua bas- 
tante produtiva e que vem aprimorando os aportes teórico-metodológicos, notadamente quanto à circunscrição do envelope de variação e ao controle de variáveis independentes mais complexas e multiníveis, refinando, por exemplo, o tratamento dispensado a aspectos socioestilísticos e às categorias de tempo, aspecto e modalidade, como podemos conferir, entre outros trabalhos, nas teses de Mariléia Reis (2003), Márluce Coan (2003) e Tatiana Pimpão (2012); e ainda nas teses de Ângela Back (2008) e Diana Bittencourt (2014), estas basicamente funcionalistas.

Como bem sinalizado na pergunta, mesmo nos restringindo aos mesmos campos teóricos - SV e FUNC de vertente norte-americana -, pode-se dizer que existem interfaces sociofuncionalistas (no plural), uma vez que abordagens distintas podem acionar diferentes aspectos de um e de outro campo. Como uma expansão daqueles trabalhos iniciais no Peul. Naro e Braga (2000) dão início a uma articulação teórica entre gramaticalização e variação, articulação que foi minuciosamente sistematizada por Maria Alice Tavares (2003) em sua tese sobre os conectores sequenciadores e, aí, daí e então, em que a autora traça o percurso diacrônico desses quatro itens em seu processo de gramaticalização e os analisa sincronicamente como variantes ou camadas de um domínio funcional. Em perspectiva similar, Cláudia Rost Snichelotto (2009) analisa a gramaticalização e o uso variável dos marcadores discursivos interacionais olha e vê em uma amostra sincrônica e outra diacrônica. Já Adriana Gibbon (2014) prioriza a gramaticalização deixando a variação em plano secundário ao analisar a trajetória da perífrase Ir + infinitivo (como em vou sair), que compartilha traços de aspecto, modalidade e tempo e cujo uso se estende para além do domínio funcional do futuro.

Nesse tipo de abordagem que contempla gramaticalização e variação, o fenômeno variável é circunscrito dentro de um domínio funcional (uma função comunicativa) constituído por diferentes camadas/formas que coexistem na expressão de uma mesma função/significação e resultam de mudança(s) por gramaticalização (cf. o princípio de estratificação de Hopper (1991)), caso em que a multifuncionalidade dos itens também é considerada na configuração do domínio funcional (GÖRSKI; TAVARES, 2017).

Entre os pontos de convergência entre SV e FUNC destacam-se alguns: prioridade atribuída à língua em uso, cuja natureza dinâmica abriga variação e mudança contínua e gradual, num movimento complementar entre sincronia e diacronia; relevância de fatores de natureza interacional situados em práticas discursivas e sociais, seja como condicionadores estilísticos (SV), seja como motivadores de mudança por gramaticalização (FUNC); importância do papel da frequência de uso, seja como índice de difusão 
sociolinguística (SV), seja para o estabelecimento da gramática (FUNC); consideração de forças em competição numa relação de complementariedade, como por exemplo, o princípio da economia, associado a menor esforço de processamento, e o princípio da iconicidade, isto é, da transparência entre forma e função, com impulso por mais informação e consequentemente maior esforço de processamento (TAVARES; GÖRSKI, 2015).

Outras articulações teórico-metodológicas contemplando gramaticalização e variação também vêm sendo feitas: Raquel Freitag (2007) propõe uma aproximação entre gramaticalização e uma abordagem evolutiva da língua, em sua tese sobre categorias verbais, mais especificamente sobre a expressão do passado imperfectivo (como em sabia e estava sabendo); Carla Valle (2014) adiciona nessa interface aspectos estilísticos e identitários, construindo variáveis complexas multidimensionais em sua tese sobre os marcadores discursivos interacionais sabe? e entende?; Marcela Bragança (2017) propõe uma articulação entre os campos variacionista, funcionalista e dialógico, a partir de reflexões sobre a expressão do tempo futuro do presente (como em sairei, vou sair, saio amanhã); entre outros trabalhos (GÖRSKI; MARTINS, a sair).

Valle e Snichelotto: Você tem trabalhado em uma perspectiva de gramaticalização como expansão, considerando os aspectos pragmáticos envolvidos no processo. Que noção de gramática é acionada nessa perspectiva e como ela se diferencia da noção de gramaticalização como redução?

Edair Görski: Em termos gerais, gramaticalização é o processo de mudança pelo qual a gramática é criada, ou o estudo desse processo, que engloba um subconjunto de mudanças linguísticas possíveis nos níveis semântico-pragmático e categorial. A literatura mais recente sobre o tema tem feito uma distinção entre duas abordagens - gramaticalização como redução e gramaticalização como expansão - que estão estritamente relacionadas com a concepção de gramática assumida (TRAUGOTT, 2010). A gramaticalização como redução é focada em "perdas" e corresponde à visão tradicional de gramaticalização, envolvendo aumento de dependência, fixação e obrigatoriedade de elementos; considera basicamente o escopo sentencial da gramática.

A gramaticalização como expansão, por outro lado, é focada em "ganhos" e corresponde a uma visão estendida de gramaticalização, que incorpora aspectos semântico-pragmáticos e extensão de contextos de uso que dizem respeito à classe hospedeira, à ampliação do escopo estrutural para além da sentença e à multifuncionalidade (HIMMELMANN, 2004). A gramaticalização como expansão está associada a uma 
concepção de gramática também alargada que abarca além do nível estrutural também o nível semântico-pragmático-discursivo. Nessa perspectiva, a gramática codifica, articuladamente, os níveis da semântica proposicional e da pragmática discursiva, e seu escopo recai "predominantemente sobre as relações de coerência entre a proposição (oração) e o contexto comunicativo mais amplo, seja o texto corrente, seja a situação de fala face a face e, nesta última, a interação falante-ouvinte” (GIVÓN, 2018, p. 35). Essa concepção estendida de gramática abriga conectores textuais e marcadores discursivos de diferentes tipos, que relacionam "um enunciado à situação do discurso, mais especificamente à interação falante-ouvinte, às atitudes do falante e/ou à organização de textos” (HEINE, 2013, p. 1211).

Valle e Snichelotto: A Sociolinguística Variacionista, vertente da Sociolinguística mais disseminada no Brasil, tem passado por mudanças significativas conectadas às novas dinâmicas da sociedade contemporânea. Na última década, você e seu grupo de pesquisa tem inovado, dedicando-se a questões estilísticas e identitárias. Qual o impacto dessas mudanças para a interface sociofuncionalista? Qual o lugar do componente social na interface?

Edair Görski: Uma visão panorâmica das mudanças pelas quais a SV tem passado desde a década de 1960, e que está diretamente relacionada a mudanças ocorridas na sociedade contemporânea, é dada pela sistematização proposta por Eckert (2012) de três ondas dos estudos variacionistas. Resumidamente: tomando o significado social e a prática analítica como critérios definidores, a autora caracteriza cada fase da seguinte maneira: (i) estudos de $1^{\text {a }}$ onda buscam estabelecer amplas correlações estatísticas entre variáveis linguísticas e macrocategorias sociais (classe socioeconômica, sexo/gênero, faixa etária, etnia) tomadas como condicionadores, em busca de padrões sociolinguísticos de uso na comunidade de fala; (ii) estudos de $2^{\mathrm{a}}$ onda já lidam com um viés etnográfico, considerando categorias socioculturais e demográficas locais, procurando captar a variação em práticas sociais de grupos; e (iii) estudos de $3^{\mathrm{a}}$ onda, com caráter ainda mais fortemente etnográfico, colocam foco na agência do sujeito e suas práticas estilísticas situados numa dinâmica dialética entre cenários micro e macrossociais.

O significado estilístico e identitário também é visto diferentemente nessas três fases variacionistas: (i) na $1^{\mathrm{a}}$ onda, o significado estilístico está vinculado a graus de atenção prestada à fala sendo avaliado em relação ao parâmetro formalidade; e a identidade do falante é associada a sua estratificação social; (ii) na $2^{\text {a }}$ onda, o significado que sobressai 
é o identitário de grupo, seja grupo social ou regional; e (iii) na $3^{\text {a }}$ onda, os significados social, estilístico e identitário se mesclam a aspectos ideológicos e culturais mais amplos e as variáveis linguísticas são vistas como indexadoras desses significados, sendo utilizadas para (re)construir e projetar personas.

Em relação a uma interface sociofuncionalisa, como já pincelado, os estudos em geral têm priorizado fenômenos de variação que são funcionalmente motivados; quando levam em conta fatores sociais, o fazem basicamente na linha dos estudos de $1^{\text {a }}$ onda e/ou observando a difusão sociolinguística de usos entre grupos. Ao voltarmos nosso interesse para questões estilísticas e identitárias nos termos do que é feito em estudos de $3^{a}$ onda, a interface sociofuncionalista precisa ser reconfigurada, basicamente no que diz respeito à dimensão sócio da SV. É nesse sentido que nosso grupo de pesquisa vem trabalhando na última década. Nessa perspectiva, Carla Valle (2014),,como mencionado na questão 2, inseriu aspectos estilísticos e identitários em sua tese sobre marcadores discursivos, ao analisar a fala de informantes da localidade pesqueira da Barra da Lagoa/ Florianópolis-SC. A dissertação de Kamilla Amaral (2020) - que analisa a emergência e expansão de usos do segmento -ste(s), agregado a bases verbais e não verbais (como em arrasaste, compreistes, porqueste, boystes), numa página de internet manauara - avança na discussão acerca do significado social e identitário visto como multicamadas que atuam simultaneamente.

Em artigos mais recentes e ainda inéditos também temos nos voltado a essas questões, buscando responder, em alguma medida, ao desafio de expandir conceitual e metodologicamente o componente social da SV na interface sociofuncionalista: discutindo sobre a dinâmica do significado social na gramaticalização a partir de uma aproximação entre gramaticalização e variação via função interpessoal da linguagem, e entre o domínio funcional e o domínio social; e propondo um modelo de domínio sociofuncional que, numa prática analítica integrada, coloque luz no significado social e sua articulação com o significado semântico-pragmático.

Valle e Snichelotto: Que impactos os novos arranjos sociais da sociedade atual (globalizada e integrada às mídias sociais) e a postura mais agentiva dos sujeitos contemporâneos têm nos estudos da variação e nos processos de gramaticalização?

Edair Görski: É fato que mudanças na sociedade têm impactos na língua. Estudos alinhados com a $3^{\mathrm{a}}$ onda variacionista refletem essas mudanças, mas também, em alguma medida, mostram uma relação dialética: a sociedade impacta a língua e a língua (os usos 
variáveis) também pode impactar a sociedade, contribuindo para alterar certos padrões de comportamento. É nesse sentido que se diz que a variação não reflete o significado social, mas o (re)constrói; e que há uma relação bidirecional entre: (re)criação de identidades/ tipos sociais pelos sujeitos agentivos $\leftrightarrow$ variação linguística; e cenário social mais amplo $\leftrightarrow$ variação linguística (ECKERT, 2016).

Considerando esse quadro, os estudos de variação enfrentam o desafio de - para além de descrever fenômenos variáveis e seus condicionamentos (socio)linguísticos em busca de padrões de regularidade na comunidade a partir de análises quantitativas (cf. $1^{\text {a }}$ onda) - encontrar caminhos metodológicos que permitam captar analiticamente a bidirecionalidade apontada acima. Ademais, se a agência dos sujeitos, seja pelo seu comportamento seja por sua linguagem, impacta os arranjos sociais e vice-versa, acreditamos que essa relação dialética também pode atuar como força motriz para movimentos de gramaticalização, especialmente de gramaticalização como extensão, em que a participação ativa dos interlocutores ganha destaque. E aqui cabe salientar o papel dos jovens e sua forte inserção nas mídias sociais, especialmente ao indexicalizarem valores sociossemióticos e identitários em suas práticas discursivas, questão da qual também temos nos ocupado.

Valle e Snichelotto: A circulação entre diferentes gêneros textuais/discursivos implica diferentes usos, estilos, formas linguísticas. É possível articular este olhar para os gêneros com a interface sociofuncionalista?

Edair Görski: A questão dos gêneros textuais/discursivos tem chamado a atenção dos sociolinguistas há bastante tempo, seja como condicionadores de processos de variação/ mudança, seja como critério organizador de amostras de análise, ou ainda como tópico de discussão teórico-metodológica com valor explanatório como se pode conferir na tese de Marcela Bragança (2017) e na coletânea recentemente organizada por Caroline Biazolli e Rosane Berlinck (2021). No lado funcionalista também aparece tanto como elemento caracterizador do locus em que se situam os fenômenos em análise, especialmente em relação à multifuncionalidade, quanto como contexto em que se observam as práticas discursivas em que os falantes, ao se engajarem com determinados propósitos sociais, negociam significados. Em se tratando de gramaticalização, uma inovação individual que é produzida expressivamente pode ter sua frequência de uso aumentada gradualmente, ou seja, rotinizada, "entre os tipos, estilos e gêneros linguísticos, bem como entre os falantes" (HOPPER; TRAUGOTT, 2003, p. 232; grifo acrescido). No âmbito da entrevista sociolinguística, por exemplo, que é tomada como um macrogênero textual que contém 
em sua composição diferentes gêneros, como narrativa de experiência pessoal e relato de opinião (TAVARES, 2014), essas configurações internas têm sido consideradas como atuantes na distribuição de formas em variação e também de itens multifuncionais.

Como já mencionado, Bragança (2017) propõe uma articulação teórico-metodológica entre os campos variacionista, funcionalista e dialógico para o tratamento de variação/mudança. $\mathrm{O}$ campo dialógico, nesse caso, diz respeito basicamente a gêneros discursivos. Então, sim, é não só possível, mas também desejável articular o olhar para os gêneros com a interface sociofuncionalista.

Valle e Snichelotto: Na sua percepção, e diante de expressivas mudanças no cenário social e educacional brasileiro, quais embates atuais entram para o campo de discussão da Sociolinguística e do Funcionalismo? Quais seriam as possíveis contribuições dessas abordagens na formação e na atuação dos/as professores/as da Educação Básica?

Edair Görski: Na trilha de respostas anteriores e considerando o cenário sociopolítico brasileiro atual e seu impacto no cenário educacional, é importante que os avanços teórico-metodológicos verificados na área da SV repercutam na formação do/a professor/a, especialmente nos cursos de Letras e Pedagogia. Nesse sentido, defendemos uma Sociolinguística Educacional (SE) voltada para a formação de um sujeito reflexivo, crítico, criativo e agentivo, que seja capaz de contribuir com mudanças no cenário social. Uma SE que, assentada no fato de que a língua é um sistema heterogêneo sócio-historicamente situado que abrange diferentes normas linguísticas e que a variação/mudança é constitutiva das línguas humanas, (i) esteja atenta à (re)construção das identidades dos sujeitos e às diferentes formas de expressão de suas (inter)subjetividades; (ii) seja norteada por valores de respeito à diversidade e de legitimação de variedades linguísticas, especialmente de usos inovadores que expressem significados sociais identitários; (iii) reconheça que tais significados são dinâmicos, multicamadas e ideologicamente atravessados. É nessa linha, enfatizando uma ou outra dessas facetas, que temos produzido algumas publicações, dentre as quais deixo como indicação de leitura para os interessados nesse tema: Görski e Coelho (2009); Görski e Freitag (2013); Görski e Valle (2019); Valle e Görski (inédito).

Em relação ao Funcionalismo, especialmente no que tange à multifuncionalidade e à gramaticalização, cabe considerar, além de motivações cognitivo-comunicativas para usos linguísticos já bem estabelecidos, também as mudanças no cenário social como potenciais forças motrizes atuando na emergência e difusão de usos inovadores. Temos buscado avançar em reflexões acerca do papel dos jovens e das mídias digitais, por exemplo, 
e de como essa questão poderia ser explorada no ensino, considerando a relação entre diferentes papéis gramaticais desempenhados por um item e funções socialmente simbólicas ou estilísticas correlacionadas (GÖRSKI; VALLE, inédito).

Articulando os dois campos numa abordagem sociofuncionalista, no que diz respeito a contribuições para a esfera da Educação Básica, além dos aspectos mencionados acima, retomo algumas considerações de Görski e Martins (a sair): Essa interface - além de fornecer ferramentas para explorar o jogo de relações entre formas e funções/significações, considerando casos de multifuncionalidade e de variação, e para correlacionar diferentes usos a contextos discursivos - fornece explicações funcionais para fenômenos em mudança e variação que levam em conta tanto a trajetória linguística dos itens como o contexto sócio-histórico de sua realização. Em outras palavras, permite lidar com a ideia de que a gramática abrange tanto usos bem estabelecidos na língua, regularizados pela recorrência, como usos emergentes, seja quanto à forma, seja quanto à (re)ssignificação, sensíveis a pressões externas à língua.

Valle e Snichelotto: Apesar do crescimento da presença feminina na pesquisa brasileira, em tempos de pandemia da COVID-19 tem ficado evidente que as mulheres ainda enfrentam condições desiguais de trabalho e dificuldades para conciliar os diferentes papéis sociais que exercem. Profa. Edair, a respeito da sua trajetória pessoal, como foi e é conciliar os papéis de professora, pesquisadora, orientadora, filha, mulher, mãe e avó?

Edair Görski: No momento em que vou responder a esta pergunta, a mídia veicula a notícia devastadora de que o Brasil chega à terrível marca de meio milhão de mortes em decorrência da COVID-19. Impossível alguém não se abalar com o forte impacto desse fato dramático!

Mas tentando, na medida do possível, abstrair momentaneamente essa dura realidade, vou focar no cerne da questão proposta: dificuldades enfrentadas especialmente pelas mulheres para conciliar os diferentes papéis sociais que lhes são requeridos. Os obstáculos que precisam ser contornados nesta época de pandemia - notadamente por mulheres que têm que harmonizar uma vida profissional cheia de exigências com uma vida familiar também repleta de demandas - não são pequenos e requerem muito esforço e determinação. Em outros tempos e diferentes situações, esse mesmo tipo de desafio para conciliar vários papéis já foi vivenciado (e continuará a ser) no dia a dia por milhões de mulheres, entre as quais me incluo.

Fazendo uma breve retrospectiva de minha trajetória, me deparo com a coexistência de sentimentos e sensações um tanto contraditórios, que, acredito, sejam compartilhados por muitas mulheres, tais como a experienciação da angústia de não acompanhar 
plenamente o desenvolvimento dos filhos pequenos; da exaustão pela carga de trabalho como fonte de renda e meio de sustento; e do prazer, ainda que esporádico à época, proporcionado, no meu caso, pela pesquisa acadêmica. Com o passar dos anos e com os filhos adultos construindo suas próprias trajetórias, o impulso de buscar compensar a ausência materna se manifestou no cuidado com os netos, numa espécie de ilusório efeito geracional retroativo; o trabalho, à medida que foi/vem exigindo mais no plano acadêmico, foi/vem também propiciando um sentimento mais acentuado de realização profissional, tanto pelo gratificante retorno dado por orientandos(as) bem-sucedidos(as) que, por sua vez, passam a desempenhar com zelo esse mesmo papel, como pela disposição para enfrentar novos desafios teóricos e práticos no campo da pesquisa.

Cenário atual: $\mathrm{O}$ longo período de isolamento/distanciamento imposto pela pandemia - não obstante o consequente afetamento da saúde física, mental e social, especialmente pela falta de movimentação e de contato direto com os familiares e amigos, e pela dureza dos fatos diários circundantes - tem me permitido uma maior concentração em leituras e avanço em reflexões teóricas, resultando em produções escritas individualmente e em coautorias, num saldo academicamente positivo. Evidentemente, o fato de eu ser aposentada, embora continue atuando como professora voluntária, reduz consideravelmente as funções institucionais, e o tempo que tenho disponível inegavelmente não se compara ao de quem está na ativa. Balanço final: Encontrar o ponto certo de equilíbrio entre a vida profissional e a vida pessoal/familiar - eis nosso maior desafio!

\section{Referências}

AMARAL, K. Emergência de usos, variação e identidade: o caso de \{-STE\} na página Tal Qual Dublagens. 2020, 255 fl. Dissertação (Mestrado em Linguística) - Programa de Pós-graduação em Linguística da Universidade Federal de Santa Catarina, Florianópolis, 2020.

BACK, A. C. P. A multifuncionalidade da forma verbal -sse no domínio tempo-aspectomodalidade: uma abordagem sincrônica. 2008, 308 f. Tese (Doutorado em Linguística) Programa de Pós-Graduação em Linguística da Universidade Federal de Santa Catarina, Florianópolis, 2008.

BIAZOLLI, C. C.; BERLINCK, R. de A. (Org.). Gêneros textuais-discursivos no estudo de processos de variação e mudança. 1. ed. Campinas, SP: Pontes Editores, 2021.

BITTENCOURT, D. L. R. de. O domínio funcional do futuro do subjuntivo: entre temporalidade e modalidade. 2014, 345 fl. Tese (Doutorado em Linguística) Programa de Pós-Graduação em Linguística da Universidade Federal de Santa Catarina, Florianópolis, 2014. 
BRAGANÇA, M. L. L. Uma proposta de articulação teórico-metodológica entre os campos variacionista, funcionalista e dialógico para o tratamento de variação/mudança: reflexões a partir da expressão do futuro do presente. 2017. 696 f. Tese (Doutorado) - Programa de Pós-graduação em Linguística da Universidade Federal de Santa Catarina, Florianópolis, 2017.

COAN, M. As categorias tempo, aspecto, modalidade e referência na significação dos pretéritos mais-que-perfeito e perfeito: correlações entre função(ões)-forma(s) em tempo real e aparente. 2003, 232 fl. Tese (Doutorado em Linguística) - Programa de Pós-Graduação em Linguística da Universidade Federal de Santa Catarina, Florianópolis, 2003.

ECKERT, P. Three waves of variation study: the emergence of meaning in the study of sociolinguistic variation. Annual Review of Anthropology, v. 41, p. 87-100, 2012.

ECKERT, P. Third wave variationism. Oxford: Oxford University Press, 2016. p. 1-16. Disponível em: https://www.oxfordhandbooks.com/view/10.1093/ oxfordhb / 9780199935345.001 .0001 / ox fordhb-9780199935345 - e27?rskey=bQ0xHO\&result=1. Acesso em: 15 out. 2019.

FREITAG, R. M. K. A expressão do passado imperfectivo no português: variação/ gramaticalização e mudança. 2007, 238 fl. Tese (Doutorado em Linguística) - Programa de Pós-Graduação em Linguística, Universidade Federal de Santa Catarina, Florianópolis, 2007.

GIBBON, A. de O. Trajetória de gramaticalização da perífrase ir (presente) + infinitivo no domínio funcional do futuro: análise sincrônica e diacrônica em amostras de fala e escrita gaúchas. 2014, 278 fl. Tese (Doutorado em Linguística) - Programa de Pós-Graduação em Linguística da Universidade Federal de Santa Catarina, Florianópolis, 2014.

GIVÓN, T. On understanding grammar. Revised edition. Amsterdam: John Benjamins, 2018.

GÖRSKI, E. M.; COELHO, I. L. Variação linguística e ensino de gramática. Working papers em Linguística, Florianópolis, v.10, n.1, p. 73-91, 2009.

GÖRSKI, E. M.; FREITAG, R. M. K. O papel da sociolinguística na formação dos professores de língua portuguesa como língua materna. In: MARTINS, M. A.; TAVARES, M. A. (Org.) Contribuições da Sociolinguística e da Linguística Histórica para o ensino de língua portuguesa. Coleção Ciências da Linguagem Aplicadas ao Ensino, volume V. Natal: EDUFRN, 2013. p. 11-52.

GÖRSKI, E. M.; TAVARES, M. A. O objeto de estudo na interface variação gramaticalização. In: BAGNO, M.; CASSEB-GALVÃO, V.; REZENDE, T. F. (Org.). Dinâmicas funcionais da mudança linguística. São Paulo: Parábola, 2017, p. 35-63.

GÖRSKI, E. M.; VALLE, C. R. M. Reconfiguração da sociolinguística variacionista e repercussões para o ensino: questões estilísticas e identitárias. Estudos linguísticos e literários, Salvador, n. 63, n. especial, 2019, p. 97-117. 
GÖRSKI, E. M.; MARTINS, M. A. Questões teórico-metodológicas da sociolinguística em interface com o gerativismo e o funcionalismo linguísticos e o ensino de língua portuguesa. In: VIEIRA, M. dos S. M; WIEDEMER, M. L. (Org.). Dossiê Grupo de Trabalho de Sociolinguística da ANPOLL, 35 anos depois: reflexões e cenários. (a sair)

GÖRSKI, E. M.; VALLE, C. R. A dinâmica do significado social na gramaticalização: desafios para uma abordagem sociofuncionalista. Inédito.

HEINE, B. On discourse markers: Grammaticalization, pragmaticalization, or something else? Linguistics, v. 51, n. 6, p. 1205-1247, 2013.

HIMMELMANN, N. P. Lexicalization and grammaticization: Opposite or orthogonal? In: BISANG, W.; HIMMELMANN, N. P.; WIEMER, B. (Ed.). What makes grammaticalization: A look from its fringes and its components. Berlin/New York: De Gruyter Mouton, 2004, p. 21-42.

HOPPER, P. On some principles in the grammaticalization. In: TRAUGOTT, E. C.; HEINE, B. (Ed.) Approaches to grammaticalization: focus on theoretical and methodological issues. v. 1. Philadelphia: John Benjamins, 1991, p. 7-35.

HOPPER, P.; TRAUGOT,, E. Grammaticalization. 2. ed. Cambridge: Cambridge University Press, 2003.

MARTINS, M. A.; ABRAÇADO, J. (Org.). Mapeamento sociolinguístico do português brasileiro. São Paulo: Contexto, 2015.

NARO, A. J.; VOTRE, S. J. Mecanismos funcionais do uso da língua: função e forma. D.E.L.T.A., São Paulo, v.8, n.2, p. 285-290, 1992.

NARO. A.; BRAGA, M. L. A interface sociolinguística/gramaticalização. Gragoatá, n. 9, p. 125-134, 2000.

PIMPÃO, T. S. Uso variável do presente no modo subjuntivo: uma análise de amostras de fala e escrita das cidades de Florianópolis e Lages nos séculos XIX e XX. 2012, 303 fl. Tese (Doutorado em Linguística) - Programa de Pós-Graduação em Linguística da Universidade Federal de Santa Catarina, Florianópolis, 2012.

REIS, M. S. dos. Atos de fala não-declarativos de comando na expressão do imperativo: a dimensão estilística da variação sob um olhar funcionalista. 2003, $212 \mathrm{fl}$. Tese (Doutorado em Linguística) - Programa de Pós-Graduação em Linguística da Universidade Federal de Santa Catarina, Florianópolis, 2003.

ROST SNICHELOTTO, C. A. "Olha" e "vê": caminhos que se entrecruzam. 2009, 408 fl. Tese (Doutorado em Linguística) - Programa de Pós-Graduação em Linguística da Universidade Federal de Santa Catarina, Florianópolis, 2009.

TAVARES, M. A. A gramaticalização de E, AÍ, DAÍ, e ENTÃO: estratificação/variação e mudança no domínio funcional da sequenciação retroativo-propulsora de informações - um estudo sociofuncionalista. 2003, 286 fl. Tese (Doutorado em Linguística) Programa de Pós-Graduação em Linguística, Universidade Federal de Santa Catarina, Florianópolis, 2003. 
TAVARES, M. A. Variação estilística e gênero textual: o caso dos gêneros textuais produzidos no macrogênero entrevista sociolinguística.In: GÖRSKI,E.M.; COELHO, I.L.; NUNES DE SOUZA, C. M. (org.). Variação estilística - reflexões teórico-metodológicas e propostas de análise. Coleção Linguística. v. 3. Florianópolis: Insular, 2014, p. 203-223.

TAVARES, M. A.; GÖRSKI, E. M. Variação e sociofuncionalismo. In: MARTINS, M. A.; ABRAÇADO, J. (Org.). Mapeamento sociolinguístico do português brasileiro. São Paulo: Contexto, 2015. p. 249-270.

TRAUGOTT, E. C. Grammaticalization. In: LURAGHI, S.; BUBENIK, V. (Ed.) Continuum companion to historical linguistics. London/New York: Continuum International Publishing Group, 2010, p. 269-283.

VALLE, C. R. M. Multifuncionalidade, mudança e variação de marcadores discursivos derivados de verbos cognitivos: forças semântico-pragmáticas, estilísticas e identitárias em competição. 2014, 415 fl. Tese (Doutorado em Linguística) - Programa de PósGraduação em Linguística da Universidade Federal de Santa Catarina, Florianópolis, 2014.

VALLE, C. R. M.; GÖRSKI, E. M. Por uma Sociolinguística Educacional socialmente constituída. Inédito.

VANDRESEN, P.; COELHO, I. L. Formação e políticas de disponibilização do banco VARSUL. In: GONÇALVES, C. A.; ALMEIDA, M. L. L. de. (Org.). Lingua Portuguesa: identidade, difusão e variabilidade. Rio de Janeiro, 2008, v. 1, p. 75-86. 